\title{
Assessing Children's Connectedness to Nature: A Mixed Method Study
}

\author{
Nor Diyana Mustapa ${ }^{1}$, Nor Zarifah Maliki ${ }^{2}$, Nor Fadzila Aziz 2, Aswati Hamzah ${ }^{3}$ \\ 1 Faculty of Architecture and Ekistics, Universiti Malaysia Kelantan \\ ${ }^{2}$ School of Housing, Building and Planning, Universiti Sains Malaysia \\ ${ }^{3}$ School of Educational Studies, Universiti Sains Malaysia \\ diyana.m@umk.edu.my, zarifah@usm.my,nfadzila@usm.my, aswati@usm.my \\ $+6011-10859544$
}

\begin{abstract}
This study aims to assess children's connectedness to nature (CTN) using a mixed-method study. This study used a sequential mixed-method approach that involved 760 children age 10-11 years old from 20 schools that include both urban and rural schools in Kedah and Pulau Pinang, Malaysia. Questionnaires were used in the quantitative part $(n=760)$, followed by focus group discussion and drawing in the qualitative part $(n=72)$. Findings showed that there are eight potential constructs can be used to measure and assess children's CTN. The directions for future research are also discussed.
\end{abstract}

Keywords: children; nature; connectedness to nature; mixed method

eISSN: 2398-42870 2020. The Authors. Published for AMER ABRA cE-Bs by e-International Publishing House, Ltd., UK. This is an open access article under the CC BYNC-ND license (http://creativecommons.org/licenses/by-nc-nd/4.0). Peer-review under responsibility of AMER (Association of Malaysian Environment-Behaviour Researchers), ABRA (Association of Behavioural Researchers on Asians) and cE-Bs (Centre for Environment-Behaviour Studies), Faculty of Architecture, Planning \& Surveying, Universiti Teknologi MARA, Malaysia.

DOI: https://doi.org/10.21834/ebpj.v5i14.2282

\subsection{Introduction}

Connectedness to nature (CTN) during childhood is crucial as it affects a child behaviour towards the environment and nature in later life as an adult. Studies have found that a strong CTN that has developed since childhood had influenced the adults' frequency of visit to green areas, perceptions of the natural environment and natural recreation activities, environmental career choices and environmental concern, as well as attitude and behaviour towards activities with nature (Mustapa, Maliki, \& Hamzah, 2018). Given the many benefits of CTN regarding individual attitudes towards nature and the environment, the question now is how an individual develops their CTN. Many studies have demonstrated that frequent experiences with and in nature during childhood are the most significant factor that contributes to an individual's CTN, which subsequently influences their environmental concerns and behaviours (Cheng \& Monroe, 2010; Duerden \& Witt, 2010; Zhang, Goodale, \& Chen, 2014). However, rapid urbanisation and population growth, which mostly occur in developing countries, have reduced children's experiences with nature especially direct experiences (Chawla \& Derr, 2012; Louv, 2008; Myers, 2012). As a consequence of disconnection with nature, children have been found to have lower CTN (Cheng \& Monroe, 2010; Ernst \& Theimer, 2011), they lack any knowledge and are unaware of nature (Aaron \& Witt, 2011; Tunstall, Tapsell, \& House, 2004), expressed negative feelings towards nature known as biophobia (Aaron \& Witt, 2011; Cohen \& Horm-Wingerd, 1993; E. O. Wilson, 1984), show a lack of appreciation and enjoyment towards the natural environment and convey more expressions of fear and dislike, especially towards wild nature (Simmons, 2006). They also rate wild nature as the least of their preferences (McAllister, Lewis, \& Murphy, 2012). Also, children who lack exposure to nature will see themselves separated from the natural world (Phenice \& Griffore, 2003) and so will have less empathy towards nature (Louv, 2008).

If today's children are disconnected from the natural world and show apathy towards the natural environment, then how will they manage and protect nature in the future? They will possibly treat nature as something to be controlled rather than protected or preserved. Hence, it is vital to identify and assess children's CTN when they are young. Higher CTN is essential to ensure a future generation that

eISSN: 2398-4287@ 2020. The Authors. Published for AMER ABRA cE-Bsby e-International Publishing House, Ltd., UK. This is an open access article under the CC BYNC-ND license (http://creativecommons.org/licenses/by-nc-nd/4.0/). Peer-review under responsibility of AMER (Association of Malaysian Environment-Behaviour Researchers), ABRA (Association of Behavioural Researchers on Asians) and cE-Bs (Centre for Environment-Behaviour Studies), Faculty of Architecture, Planning \& Surveying, UniversitiTeknologi MARA, Malaysia.

DOI: https://doi.org/10.21834/ebpj.v5i14.2282 
cares for and will sustainably manage the environment and nature. Extensive studies have discussed the importance of CTN among children, and many instruments have been developed to measure children's CTN; however, little is known on the underlying constructs of children's CTN. Previous studies mostly used a quantitative approach to measure children's CTN using various constructs that adapted from the adults' instrument. As children view things differently from adults (Sebba, 1991; R. Wilson, 1997), it is crucial to understand CTN from children's perspectives. Children see nature in a direct manner and not in an abstract way (McDevitt \& Ormrod, 2002). Even though the quantitative instrument is essential to generalise the results and to identify the position of children's CTN along a continuum, many researchers have suggested that the qualitative approach is the best method to use with children. Therefore, this study aims to identify the constructs of CTN to be captured among children using a mixed-method approach.

\subsection{Literature Review}

\subsection{Connectedness to Nature Concept and Measurement}

The notion of being connected to nature is a psychological one and has been conceptualised in various ways involving three psychological domains, specifically, cognitive, affective, and behavioural domains. Some researchers have defined CTN as a combination of the three psychological domains (e.g., Clayton, 2003; Nisbet, Zelenski and Murphy, 2008, Richardson et al., 2019) while others have highlighted only one (e.g., Mayer \& Frantz, 2004) or two of them (e.g., Cheng \& Monroe, 2010; Kals, Schumacher, \& Montada, 1999). Several concepts and instruments have been introduced to measure CTN, but the question is, which one is the most reliable? As suggested in recent studies, a multi-dimensional approach seems more reliable in measuring CTN and offers a better performance to predict behaviour (Restall \& Conrad, 2015; Tam, 2013). A uni-dimensional approach has limitations to explain attitudes and behaviours (Johnson \& Manoli, 2008). Hence, this study conceptualises CTN by integrating all three psychological domains, namely, cognitive, affective, and behavioural, in one framework rather than discussing them separately. This conceptualisation using three domains is consistent with Schultz's (2002) idea that an individual's belief on their CTN has cognitive, affective, and behavioural components.

\subsection{Connectedness to Nature Constructs}

This study has categorised together the constructs that have similar meanings and has identified six potential constructs that can be used to measure CTN. The constructs were identified from previous instruments, as well as from qualitative findings related to children and nature. The constructs are nature awareness, environmental identity, enjoyment in nature, empathy towards nature, interest in nature activities, and interest in natural places. Nature awareness refers to the cognitive domain of people's awareness of the importance of nature. Meanwhile, environmental identity represents the cognitive domain of a person's belief of her/himself as part of nature (Clayton, 2003). Enjoyment in nature is an affective domain on people's emotions and feelings of being in nature. Another construct in the affective domain is empathy towards nature. Empathy has been defined as the understanding and sharing of another person's or object's emotional experience and one of the essential parts of CTN (Schulz, 2001). For the behavioural domain, children's CTN can be exhibited through their interest in nature activities (Cheng and Monroe, 2010). Interest in natural spaces is another construct under the behavioural domain that presents children's inclination to have natural elements in areas and spaces.

\subsection{Methodology}

\subsection{Participants and Methods}

This study used a sequential mixed-method approach that involved 760 children age 10-11 years old from 20 schools that include both urban and rural schools in Kedah and Pulau Pinang, Malaysia. The sample for the quantitative part was chosen using stratified random sampling, and sample for the qualitative part was selected using purposeful sampling. Specifically, an intensity sampling strategy was used to select the sample based on the quantitative results. Questionnaires were used in the quantitative part ( $n=760$ ), followed by focus group discussion and drawing in the qualitative part $(n=72)$. For the qualitative part, twenty-four children from the low, moderate and high level of CTN were selected, giving a total sample of 72 .

\subsection{Questionnaire Development}

Children's CTN was measured through six constructs, which were nature dependence, sense of responsibility, enjoyment in nature, empathy towards nature, interest in nature activities, and interest in natural spaces. Overall, there were 26 items, and the items for each construct were adapted from previous instruments of CTN.

\subsection{Analyses}

The data were analysed using IBM SPSS Statistics Version 22 and Microsoft Excel. Descriptive analysis using the mean score and standard deviation were used to categorise the score of children's CTN into the low, moderate and high-level group. Inferential analysis using factor analysis was used to group the inter-correlated items of CTN into constructs. Meanwhile, content analysis was used to analyse the qualitative data from the focus group discussions and drawing activities to explore how children from low, moderate, and 
high-level groups differ in connection to nature. Content analysis was performed to cross check the underlying constructs of CTN with the quantitative results.

\subsection{Preparing for Data Analysis}

Factor analysis has been used for construct validity. The results of Barlett's test of sphericity and Kaiser- Maiyer-Olkin (KMO) for CTN in the actual study indicate that factor analysis is appropriate. Barlett's test of sphericity for CTN is significant, with a value of 0.000 . The Kaiser-Maiyer-Olkin (KMO) measure of sampling adequacy exceeds 0.6 with a value of 0.83 . Component 1 is named as empathy towards nature, component 2 is named as a sense of responsibility, component 3 is named as enjoyment in nature, component 4 is named as nature dependence, component 5 is named as interest in natural spaces, and component 6 is named as interest in nature activities. Items for environmental identity do not have the highest significant loading; hence, environmental identity is not one of the main constructs of CTN. The results for Cronbach's alpha for each construct was acceptable. Thus, the constructs delineated from factor analysis are appropriate and reliable.

A pilot study has been conducted for the qualitative part where the children were asked questions related to the focus group discussion. The children were also asked to draw their dream house and design their home yard. The researcher tested the flow of the focus group questions and found that the children understood the instructions given and the questions asked. However, a few questions for the focus group needed to be revised. Regarding the drawing, the children drew according to the instruction given.

\subsection{Findings}

\subsection{Quantitative Results}

\subsubsection{Level of Children's Connectedness to Nature}

The mean for each group is calculated using Mean $\pm 1 S D(M=3.31$ and $S D=0.34)$. Thus, the means for each group are as follows: low level $(\mathrm{M}<=2.97)$, moderate level $(2.97<M<3.65)$, and high level $(M>=3.65)$. As shown in Table 1, more than two thirds $(66.8 \%)$ of the children have a moderate level of CTN, followed by $16.7 \%$ of the children with a high level of CTN, and $16.4 \%$ of the children with a low level of CTN. The result shows that most of the children have a moderate level of CTN.

Table 1. Percentage for Low, Moderate, and High Level of CTN

\begin{tabular}{llcc}
\hline & CTN level & Frequency & Percentage \\
\hline Low level & $(\mathrm{M}<=2.97)$ & 125 & $16.4 \%$ \\
\hline Moderate level & $(2.97<\mathrm{M}<3.65)$ & 508 & $66.8 \%$ \\
\hline High level & $(\mathrm{M}>=3.65)$ & 127 & $16.7 \%$ \\
\hline
\end{tabular}

\subsubsection{Level of Constructs for Connectedness to Nature}

Table 2: Mean Scores for Each Construct of CTN

\begin{tabular}{cccc}
\hline Constructs & Number of items & Mean & Standard deviation \\
\hline Enjoyment in Nature & 3 & 3.51 & 0.92 \\
\hline Nature Dependence & 6 & 3.29 & 0.45 \\
\hline Sense of Responsibility & 4 & 3.28 & 0.45 \\
\hline Empathy Towards Nature & 5 & 3.25 & 0.49 \\
\hline Interest in Natural Spaces & 5 & 3.19 & 0.37 \\
\hline Interest in Nature Activities & 3 & 2.93 & 0.70 \\
\hline
\end{tabular}

Based on Table 2, the constructs that rank from the highest mean scores to the lowest mean scores are enjoyment in nature $(M=3.51$, $S D=0.92)$, nature dependence $(M=3.29 ; S D=0.45)$, sense of responsibility $(M=3.28 ; S D=0.45)$, empathy towards nature $(M=3.25, S D$; $0.49)$, interest in natural spaces $(M=3.19 ; S D=0.37)$, and interest in nature activities $(M=2.93, S D=0.70)$. This finding implies that the affective domain and cognitive domain of CTN are the domains that are most reflected in children's CTN. These are followed by the behavioural domain. Further analysis of the mean scores for each construct according to groups (low, moderate, and high level of CTN) is presented in Table 3. Table 4 further provides the rank of the constructs from high to low mean scores for each group (low, moderate, and high level of CTN).

Table 3: Mean Scores for Each Construct According to Low, Moderate, and High Level of CTN Groups

\begin{tabular}{cccc}
\hline & & Group/ Mean & High \\
\cline { 2 - 4 } Constructs & Low & Moderate & 3.85 \\
\hline Enjoyment in Nature & 3.10 & 3.52 & 3.91 \\
\hline Empathy Towards Nature & 2.32 & 3.31 & 3.77 \\
\hline Nature Dependence & 2.78 & 3.30 & 3.76 \\
\hline Sense of Responsibility & 2.80 & 3.27 & 3.42 \\
\hline Interest in Natural Spaces & 2.85 & 3.21 & 3.59 \\
\hline Interest in Nature Activities & 2.34 & 2.91 & \\
\hline
\end{tabular}


Table 4: Arrangement of CTN Constructs from High to Low Mean Scores

\begin{tabular}{cccc}
\hline $\begin{array}{c}\text { Mean Scores/ } \\
\text { Groups }\end{array}$ & \multicolumn{1}{c}{ Low } & Moderate & High \\
\hline High & Enjoyment in Nature & Enjoyment in Nature & Empathy Towards Nature \\
\cline { 2 - 4 } & Interest in Natural Spaces & Empathy towards Nature & Enjoyment in Nature \\
\cline { 2 - 4 } & Sense of Responsibility & Nature Dependence & Nature Dependence \\
\cline { 2 - 4 } & Nature Dependence & Sense of Responsibility & Sense of Responsibility \\
\cline { 2 - 4 } Low & Interest in Nature activities & Interest in Natural Spaces & Interest in Nature activities \\
\cline { 2 - 4 } & Empathy Towards Nature & Interest in Nature activities & Interest in Natural Spaces \\
\hline
\end{tabular}

Based on Table 4, the enjoyment in nature construct has the highest mean scores for the low and moderate groups of CTN, whereas, for the high level of CTN group, the construct that has the highest mean score is empathy towards nature. The construct of enjoyment in nature and empathy towards nature are the two constructs that have the highest mean scores for both the moderate and high levels of CTN groups. Similarly, for the low level of CTN group, enjoyment in nature has the highest mean score, but empathy towards nature has the lowest mean score. The constructs of nature dependence and sense of responsibility are located at the same level (third and fourth place) for all three groups. The constructs that have lower mean scores for all three groups are interest in nature activities and interest in natural spaces. However, for the low level of CTN group, interest in natural spaces has the second highest mean scores.

This finding suggests that the most reflected construct in children's CTN is empathy towards nature. Empathy towards nature is the crucial indicator of children's CTN since the high level of CTN group has the highest mean of empathy towards nature. In contrast, for the low level of CTN group, empathy towards nature has the lowest mean score. This is followed by enjoyment in nature, nature dependence, sense of responsibility, interest in natural spaces, and interest in nature activities.

\subsection{Qualitative Results}

\subsubsection{The Constructs of Children's Connectedness to Nature}

Eight themes have been identified from children's responses regarding their CTN. Six of the themes are similar to the constructs identified in the quantitative results, which are nature dependence, sense of responsibility, empathy towards nature, enjoyment in nature, interest in natural spaces, and interest in nature activities. Two new themes emerged from the qualitative data, namely, nature identification and negative affiliation. Nature identification refers to children's knowledge of specific natural elements, such as plants and animals. Negative affiliation is the negative feelings that children expressed towards nature.

Table 5: Themes, Sub-themes and Examples of Responses for Each Theme or Constructs of CTN

\begin{tabular}{|c|c|c|}
\hline \multirow{2}{*}{$\begin{array}{l}\text { Themes/ Constructs } \\
\text { Nature Identification }\end{array}$} & Sub-themes & Example of responses \\
\hline & $\begin{array}{l}\text { - Plant identification } \\
\text { - Fish identification } \\
\text { - Bird identification }\end{array}$ & $\begin{array}{l}\text { "... bougainvillea, ixora, lime, lemongrass..." } \\
\text { "I have caught climbing perch, snakehead and kissing } \\
\text { gourami fish" } \\
\text { "I have experience caught Bulbul bird" }\end{array}$ \\
\hline Nature Dependence & $\begin{array}{l}\text { - Life necessities } \\
\text { - Natural Disaster Prevention } \\
\text { - Material } \\
\text { - Medicine } \\
\text { - Psychological needs } \\
\end{array}$ & $\begin{array}{l}\text { "Nature provides us with food and drink." } \\
\text { "We need nature to prevent landslides." } \\
\text { "We can use trees to make paper and planks" } \\
\text { "We can use plants to make herbs." } \\
\text { "We need nature to relieve stress." }\end{array}$ \\
\hline Sense of Responsibility & $\begin{array}{l}\text { - Humans need } \\
\text { - Concern towards animals } \\
\text { - Ecosystem } \\
\text { - Environmental issues } \\
\text { - Practices } \\
\text { - Spiritual } \\
\end{array}$ & $\begin{array}{l}\text { "We need nature for oxygen." } \\
\text { "We cannot destroy nature because animals will lose their } \\
\text { habitats." } \\
\text { "If we destroy nature, the ecosystem will not be balanced." } \\
\text { "If we fell more trees, the earth will become hotter." } \\
\text { "I help my father to sweep the rubbish." } \\
\text { "Nature is living things created by God." }\end{array}$ \\
\hline Empathy towards Nature & $\begin{array}{l}\text { - Anger } \\
\text { - Sadness } \\
\text { - Sympathy } \\
\text { - Aversion } \\
\text { - Disregard }\end{array}$ & $\begin{array}{l}\text { "I feel angry and sad seeing people felling } \\
\text { trees." } \\
\text { "I feel sympathy when animals lose their habitat due to } \\
\text { deforestation." } \\
\text { "I do not like seeing people felling trees." } \\
\text { "I do not care if people fell the trees." }\end{array}$ \\
\hline Enjoyment in Nature & $\begin{array}{l}\text { - Excitement } \\
\text { - Refreshment }\end{array}$ & $\begin{array}{l}\text { "I feel happy when I go to the beach." } \\
\text { "The sound of water makes me feel calm." }\end{array}$ \\
\hline $\begin{array}{l}\text { Interest in natural } \\
\text { Spaces }\end{array}$ & $\begin{array}{l}\text { - Plants } \\
\text { - Scenery } \\
\text { - Animals } \\
\text { - Hardscape } \\
\text { - Relaxation }\end{array}$ & $\begin{array}{l}\text { "My dream house has flowers and grass." } \\
\text { "My dream house is located nearby a hill and a waterfall." } \\
\text { "I want a pet rabbit" } \\
\text { "My dream house has fish pond" } \\
\text { "My dream house has jogging track" }\end{array}$ \\
\hline
\end{tabular}




\begin{tabular}{lll} 
& \multicolumn{2}{c}{ Continued Table 5} \\
\hline Themes/ Constructs & Sub-themes & Example of responses \\
\hline Interest in Nature & - Activities with Plants & "I like to climb trees and plant trees." \\
Activities & "Activities with Animals & "I like to go fishing." \\
& - Water Activities & "I have no camping experience, but I want to join in the \\
& - Adventurous Activities & future." \\
& - Uninterested* & "I do not want to join camping activity." \\
& - Fear & "I am afraid to go near the beach." \\
& - Disgust & "I do not like gardening ...My hands will get dirty." \\
& - Uncomfortable & "I do not like camping...It is hot." \\
& - Bored & "I feel bored watching National Geographic."
\end{tabular}

${ }^{*}$ Negative themes and sub-themes

Further analysis of the themes was conducted to explore the differences between groups of low, moderate, and high levels of CTN. The percentage of children who gave responses for each theme is presented in Table 6 and Figure 1.

Table 6: Percentage for Each Theme According to Low, Moderate, and High Level of CTN Groups

\begin{tabular}{lccc}
\hline Themes/ Groups & \multicolumn{2}{c}{ Percentage $(\%)$} \\
\cline { 2 - 4 } & Low $(\mathrm{n}=24)$ & Moderate $(\mathrm{n}=24)$ & High $(\mathrm{n}=24)$ \\
\hline Nature Identification (NI) & 50.0 & 62.5 & 79.2 \\
\hline Nature Dependence (ND) & 87.5 & 100.0 & 100.0 \\
\hline Sense of Responsibility (SR) & 70.8 & 100.0 & 100.0 \\
\hline Empathy towards Nature (EM) & 87.5 & 83.3 & 100.0 \\
\hline Enjoyment in Nature (EN) & 79.2 & 91.7 & 100.0 \\
\hline Negative Affiliation (NA) & 58.3 & 8.3 & 0.0 \\
\hline Interest in Natural Spaces (INS) & 70.8 & 87.5 & 91.7 \\
\hline Interest in Nature Activities (INA) & 91.7 & 91.7 & 100.0 \\
\hline
\end{tabular}

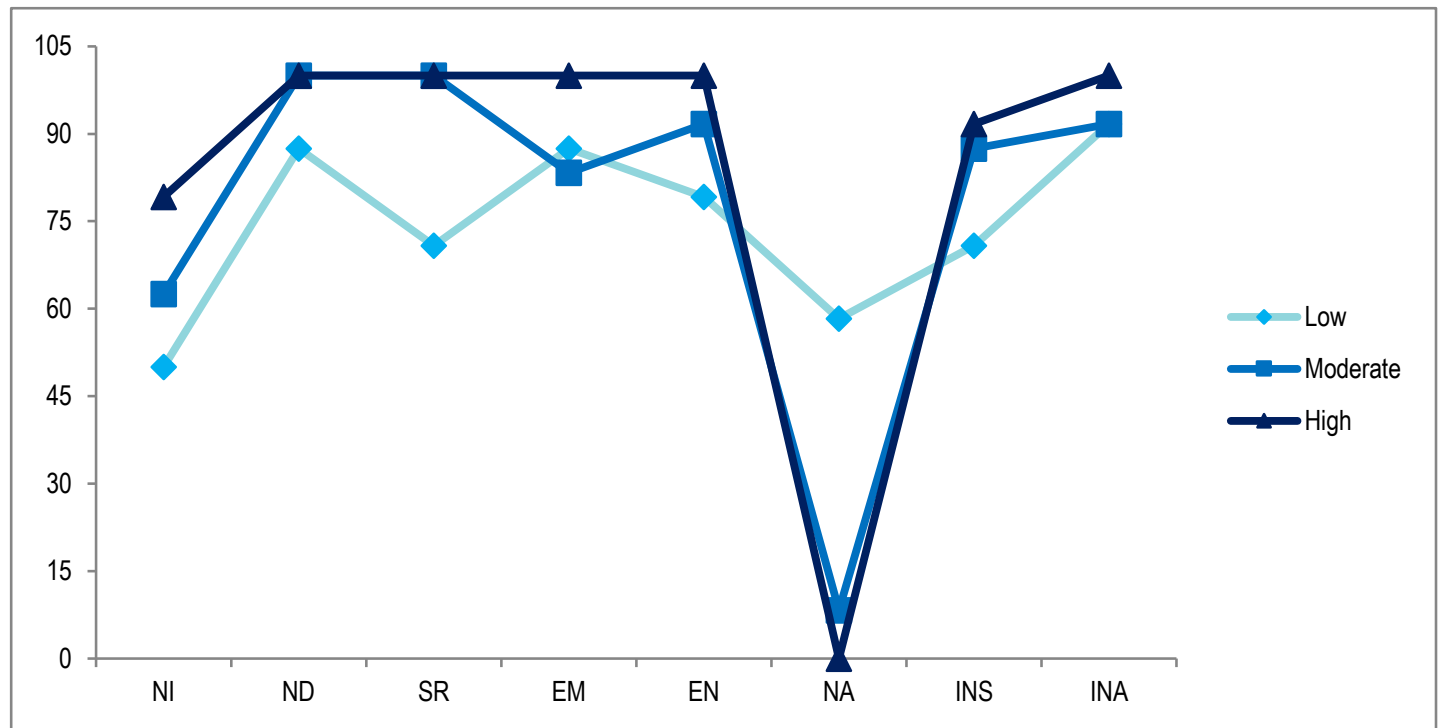

Figure 1: Chart of Percentage for Each Theme According to Low, Moderate, and High Level of CTN Groups

It is apparent from Figure 1 that the high level of CTN group has a slightly higher percentage than the moderate and low level of CTN groups for five of the themes, which are nature identification, empathy towards nature, enjoyment in nature, interest in natural spaces, and interest in nature activities. For another two themes, namely, nature dependence and sense of responsibility, the percentages for the high level of CTN group and the moderate level of CTN group are the same, but higher than the low level of CTN group. Meanwhile, for negative affiliation, the low level of CTN group has a higher percentage compared to the moderate and high level of CTN groups.

In sum, these findings suggest that CTN can be assessed through all eight themes, namely, nature identification, nature dependence, sense of responsibility, empathy towards nature, enjoyment in nature, negative affiliation, interest in nature activities, and interest in natural spaces. These findings support the quantitative results for the underlying constructs to measure children's CTN with an additional two constructs.

\subsection{Discussion}

Overall, the findings confirm that CTN can be reflected through children's cognitive, affective, and behavioural intentions. This 
conceptualisation supports Schulz's (2000) idea CTN includes all three psychological domains: cognitive, affective, and behavioural. The findings also validate the construct from the quantitative analysis and found new constructs. The findings for each construct confirm that CTN can be measured through all eight constructs found in the qualitative part where the high level of CTN group has a slightly higher percentage, followed by the moderate and the low level of CTN groups. The findings also reveal that the construct that has the highest mean score that reflects children's CTN is empathy towards nature, the children's feeling when seeing nature being destroyed. This can be clearly seen, for the high level of CTN group, empathy towards nature has the highest mean score, whereas, for the low level of CTN group, the empathy towards nature construct has the lowest mean score. In other words, children in the high-level group have more empathy towards nature than children from the moderate and low-level group. Hence, this finding indicates that empathy towards nature is the main indicator to measure children's CTN. These findings are in agreement with previous studies that described empathy towards nature as playing an important part in CTN (Schulz, 2001). This is followed by the other constructs of enjoyment in nature, nature dependence, sense of responsibility, interest in natural spaces, and interest in nature activities. These findings further suggest that the affective domain is the main indicator to exhibit children's CTN, and this is followed by the cognitive or behavioural domain. Besides, the findings from the qualitative part confirm that children see nature in a direct manner and not in an abstract way (McDevitt \& Ormrod, 2002); therefore, children's CTN should be measured in a direct way. Findings also suggest that drawing is an effective method to be used with children.

\subsection{Conclusion \& Recommendations}

This study gives new insights on the underlying constructs that can be used to measure and assess children's CTN. However, several limitations need to be addressed, such as this study only involved children aged 10 and 11 years old and only conducted at Sekolah Kebangsaan (SK). Hence, future research needs to be performed with children aged 7 to 10 years old and at different types of school. Also, future research should explore the factors that influence children's CTN as there is an apparent difference between children from the high, moderate and low level of CTN.

\section{Acknowledgements}

The authors would like to acknowledge the Fundamental Research Grant Scheme (FRGS) under the Ministry of Education (MOE) for funding this research and Short-Term Grant (SJGP) University Malaysia Kelantan for the continuous support.

\section{References}

Aaron, R. F., \& Witt, P. A. (2011). Urban students' definitions and perceptions of nature. Children Youth and Environments, 21(2), $145-167$.

Chawla, L., \& Derr, V. (2012). The development of conservation behaviours in childhood and youth. In The Oxford Handbook of Environmental and Conservation Psychology (pp. 527-555). New York: Oxford University Press.

Cheng, J. C.-H., \& Monroe, M. C. (2010). Connection to nature: Children's affective attitude toward nature. Environment and Behavior, 44(1), 31-49.

Clayton, S. (2003). Environmental identity: A conceptual and an operational definition. In S. Clayton \& S. Opotow (Eds.), Identity and the Natural Environment: The Psychological Significance of Nature (pp. 45-65). Cambridge, MA: MIT Press.

Cohen, S., \& Horm-Wingerd, D. (1993). Children and the environment: Ecological awareness among preschool children. Environment and Behavior, 25(1), 103-120.

Duerden, M. D., \& Witt, P. A. (2010). The impact of direct and indirect experiences on the development of environmental knowledge, attitudes, and behavior. Journal of Environmental Psychology, 30(4), 379-392.

Ernst, J., \& Theimer, S. (2011). Evaluating the effects of environmental education programming on connectedness to nature. Environmental Education Research, 17(5), $577-598$.

Johnson, B., \& Manoli, C. C. (2008). Using bogner and wiseman's model of ecological values to measure the impact of an earth education programme on children's environmental perceptions. Environmental Education Research, 14(2), 115-127.

Kals, E., Schumacher, D., \& Montada, L. (1999). Emotional affinity toward nature as a motivational basis to protect nature. Environment and Behavior, 31(2), $178-202$.

Louv, R. (2008). Last children in the woods. Saving our children from nature-deficit disorder. Chapel Hill, NC: Algonquin Books.

Mayer, F. S., \& Frantz, C. M. (2004). The connectedness to nature scale: A measure of individuals' feeling in community with nature. Journal of Environmental Psychology, 24(4), 503-515.

McAllister, C., Lewis, J., \& Murphy, S. (2012). The green grass grew all around: Rethinking urban natural spaces with children in mind. Children, Youth and Environments, 22(2), 164-193.

McDevitt, T. M., \& Ormrod, J. E. (2002). Child development and education. Upper Saddle River, NJ: Pearson Prentice Hall.

Mustapa, N. D., Maliki, N. Z., \& Hamzah, A. (2018). Benefits of Nature on Children 's Developmental Needs : A Review. Asian Journal of Behavioural Studies, 3(12), 31. 
Myers, O. E. (2012). Children and nature. In The Oxford Handbook of Environmental and Conservation Psychology (pp. 113-127). New York: Oxford University Press.

Nisbet, E. K., Zelenski, J. M., \& Murphy, S. A. (2008). The nature relatedness scale: Linking individuals' connection with nature to environmental concern and nehavior. Environment and Behavior, 41(5), 715-740.

Phenice, L. A., \& Griffore, R. J. (2003). Young children and the natural world. Contemporary Issues in Early Childhood, 4(2), 167-171.

Richardson, M. et al. (2019) A Measure of Nature Connectedness for Children and Adults : Validation, Performance , and Insights. Sustainability, 11(3250), 1-16.

Restall, B., \& Conrad, E. (2015). A literature review of connectedness to nature and its potential for environmental management. Journal of Environmental Management, $159,264-278$

Schultz, P. W. (2002). Inclusion with nature: The psychology of human-nature relations. In P. Schmuck \& P. W. Schultz (Eds.), Psychology of Sustainable Development (pp. 62-78). Boston: Kluwer Academic.

Sebba, R. (1991). The landscapes of childhood: The reflection of childhood's environment in adult memories and in children's attitudes. Environment and Behavior, 23(4), 395-422.

Simmons, D. A. (2006). Urban children's preferences for nature: Lessons for environmental education. Children's Environment, 11(3), 194-203.

Tam, K.-P. (2013). Concepts and measures related to connection to nature: Similarities and differences. Journal of Environmental Psychology, 34, 64-78.

Tunstall, S., Tapsell, S., \& House, M. (2004). Children's perceptions of river landscapes and play: What children's photographs reveal. Landscape Research, 29(2), 181204.

Wilson, E. O. (1984). Biophilia. Cambridge, MA: Harvard University Press.

Wilson, R. (1997). A sense of place. Early Childhood Education Journal, 24(3), 191-194.

Zhang, W., Goodale, E., \& Chen, J. (2014). How contact with nature affects children's biophilia, biophobia and conservation attitude in China. Biological Conservation $177,109-116$ 